Adrian Liston

Sylvie Lesage

Daniel H. D. Gray

Richard L. Boyd

Christopher C. Goodnow

\section{Genetic lesions in T-cell tolerance and thresholds for autoimmunity}

Authors' addresses

Adrian Liston ${ }^{1}$, Sylvie Lesage ${ }^{1,2}$, Daniel H. D. Gray ${ }^{3}$, Richard L. Boyd ${ }^{3}$, Christopher C. Goodnow ${ }^{1}$

${ }^{1}$ John Curtin School of Medical Research and The Australian Phenomics Facility, The Australian

National University, Canberra, Australia.

${ }^{2}$ CHUM Research Center, Montreal University, Montreal, Canada.

${ }^{3}$ Department of Pathology and Immunology, Monash University, Melbourne, Australia.

Correspondence to:

Christoper C. Goodnow

Division of Immunology and Genetics

The John Curtin School of Medical Research

P.O. Box 334, Mills Road

Canberra, ACT 2601

Australia

Tel.: +61261253621

Fax: +61261258512

E-mail: chris.goodnow@anu.edu.au
Immunological Reviews 2005

Vol. 204: 87-101

Printed in Singapore. All rights reserved

Copyright (C) Blackwell Munksgaard 2005

Immunological Reviews

0105-2896
Summary: The cause of common organ-specific autoimmune diseases is poorly understood because of genetic and cellular complexity in humans and animals. Recent advances in the understanding of the mechanisms of the defects underlying autoimmune disease in autoimmune polyendocrinopathy syndrome type 1 and non-obese diabetic mice suggest that failures in central tolerance play a key role in predisposition towards organ-specific autoimmunity. The lessons from such rare monogenic autoimmune disorders and well-characterized polygenic traits demonstrate how subtle quantitative trait loci can result in large changes in the susceptibility to autoimmunity. These data allow us to propose a model relating efficiency of thymic deletion to T-cell tolerance and susceptibility to autoimmunity.

\section{Introduction}

Autoimmune diseases, despite being directed against different target antigens and tissues, often cluster together in individuals and families. For example, the relatives of patients with type 1 diabetes (1), rheumatoid arthritis (2, 3), and multiple sclerosis (4) show a higher susceptibility for autoimmunity, and patients suffering one autoimmune disease, such as type 1 diabetes, have a greater chance of suffering additional autoimmune diseases, such as thyroiditis $(5,6)$. This clustering indicates the potential for a broad-spectrum genetic defect in immunological tolerance mechanisms, but the nature of the cellular or genetic defects have been difficult to elucidate. However, recent gains in the understanding of rare monogenic disorders in humans and highly characterized polygenic disorders in mice are shedding light on the parameters involved in susceptibility to autoimmunity. Study of minor variants in these parameters thus provides a model for how multiple minor effects distort the susceptibility towards autoimmunity, and it suggests why some diseasesusceptibility loci are linked to multiple diseases, while others are involved in a single disease only.

Burnet's original concept of clonal deletion as a mechanism to explain actively acquired self-tolerance was the first mechanism to be experimentally established (7). Thymocytes rearrange their T-cell receptor (TCR) genes as they differentiate from 
$\mathrm{CD} 4^{-} \mathrm{CD} 8^{-}$double-negative progenitors into immature $\mathrm{CD} 4{ }^{+} \mathrm{CD} 8{ }^{+}$double-positive (DP) $\mathrm{T}$ cells. Each DP thymocyte thus expresses a unique TCR on its surface. T cells bearing TCRs that bind self-antigen and major histocompatibility complex (MHC) too strongly at this point are triggered to die by TCR signaling, in a manner incompletely understood but known to require the BH3-only Bcl-2 family member $\operatorname{Bim}(8,9)$. Alternatively, cells with TCRs that bind self MHC too weakly fail to receive any TCR signal and die by a separate process of 'neglect'. Only those $\mathrm{T}$ cells with TCRs that react with low avidity with self-MHC transmit a particular type of TCR signal that promotes 'positive selection' into mature $\mathrm{CD} 4{ }^{+} \mathrm{CD} 8^{-}$or $\mathrm{CD}^{-} \mathrm{CD} 8^{+}$ single-positive (SP) $\mathrm{T}$ cells that then emigrate to the peripheral lymphoid tissues of the body.

In the case of tolerance to organ-specific antigens, two chief reasons contributed to the view that thymic deletion would be of little significance compared to peripheral tolerance mechanisms. Foremost was the evidence that major protein components of specific organs, such insulin in the pancreatic islets or thyroglobulin in the thyroid gland, are present at insignificant quantities in the thymus. Even in the face of growing evidence for trace expression of these and many other organ-specific components in rare cells in the thymic medullary epithelial meshwork $(10,11)$, it was difficult to see how this could delete more than a small fraction of autoreactive thymocytes before export to the periphery. That view was buttressed by the second reason for disfavoring thymic deletion, namely the ready isolation of $\mathrm{T}$ cells and clones in the periphery of autoimmune-prone mice with sufficient autoreactivity to actively transfer disease to lymphopenic recipients.

The beauty of classical genetic analysis, which starts with a phenotype and proceeds to explain it in cellular and molecular terms, is that it is relatively immune to the conceptual biases that are intrinsic to the elegant but artificed hypothesis-testing experiments in immunology. Here, we review our experience analyzing the autoimmune phenotypes in a Mendelian autoimmune disorder, autoimmune polyendocrine syndrome 1 (APS-1), and in the non-obese diabetic (NOD) mouse. Surprisingly, both genetic approaches indicate that thymic deletion is central to organ-specific tolerance. In addition, the mechanisms behind both of these autoimmune phenotypes are distinct, and they indicate that each parameter in central tolerance is highly sensitive to small genetic changes, rather than being robustly buffered against change.

\section{Tracing the cellular effects of autoimmune susceptibility genes}

To trace the cellular defects caused by autoimmune susceptibility genes, our studies have used the 3A9 TCR that has a high affinity for peptide 46-61 of hen egg lysozyme (HEL) bound to I-A $\mathrm{A}^{\mathrm{k}}$ (12). In 3 A9 TCR transgenic mice crossed with HEL transgenic mice, thymic clonal deletion results in a reduction in the number of HEL-reactive $\mathrm{T}$ cells. When the HEL transgene is expressed under the control of different organspecific or ubiquitous promoters, the level of clonal deletion in the double-transgenic mice correlates with the thymic expression levels (Fig. 1). The titration experiments show that for thymocytes of a fixed avidity, increasing antigen exposure results in a higher level of negative selection, giving a doseresponse curve.

The best-characterized HEL transgene in this system is that of HEL driven by the rat insulin promoter (RIP) (insHEL). The RIP is strongly active in the $\beta$-islets and weakly active in the testes and the thymic stroma (13). Transplantation experiments have shown that expression in the thymus is both necessary and sufficient for negative selection of 3A9-bearing cells (Fig. 2), whereas bone-marrow chimeric experiments have demonstrated that thymic dendritic cells are unable to produce biologically relevant concentrations of HEL (Fig.3). Together, these data indicate that the thymic stromal cells are responsible for the production of tolerogenic HEL. Recent studies have shown that the loss of the autoimmune regulator (Aire) gene results in a strong decrease in the transcription of both the endogenous insulin gene $(13,14)$ and the RIP-driven transgene (13), and in the case of the transgene at least, this decrease in ectopic transcript dramatically reduces the tolerogenic capacity of the thymic stroma (15).

Besides clonal deletion, there are additional levels of central tolerance that can be induced by the presence of self-antigen driven by the insulin promoter, with the enrichment of regulatory cells (Fig. 4) and the active induction of TCR downregulation (15) and anergy (16). The increased proportion of $\mathrm{CD}_{25}{ }^{+}$thymocytes by exposure to self-antigen in this system appears to be due to an enhanced resistance to negative selection in $\mathrm{CD} 25^{+}$cells, rather than an active conversion of $\mathrm{CD} 25^{-}$ cells to $\mathrm{CD} 25^{+}$cells, as the absolute number of $\mathrm{CD} 25^{+}$cells does not increase. Furthermore, it does not appear that the $\mathrm{CD}_{2} 5^{+}$thymocytes present bear a TCR of modulated affinity for self-antigen, as the number of $\mathrm{CD} 25^{+}$cells does not change on a background where the $\mathrm{T}$ cells are unable to rearrange endogenous $\operatorname{TCR} \alpha$ chains, or $\operatorname{TCR} \alpha$ and $\beta$ chains (Fig. 4). This finding contrasts with other double-transgenic models in which thymocytes can be actively converted to $\mathrm{CD} 25^{+}$by exposure to self-antigen (17-19), which appears to occur in thymocytes carrying a high-affinity TCR (19).

One model that fits these data sets is one where there is a regulatory compartment of a fixed size, with the conversion of 


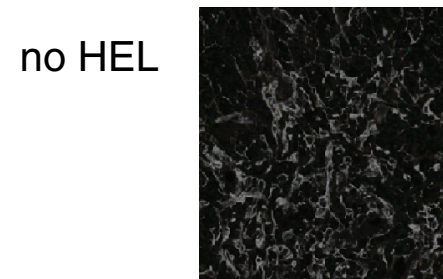

insHEL

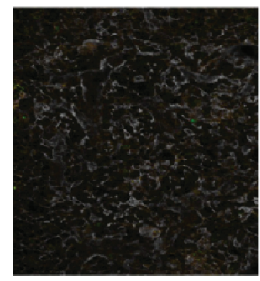

TgHEL

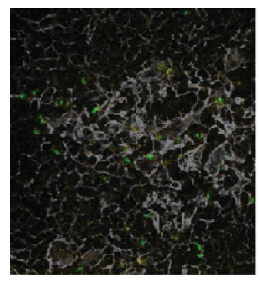

\section{MtHEL}

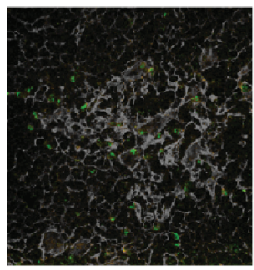

\section{H2KHEL}

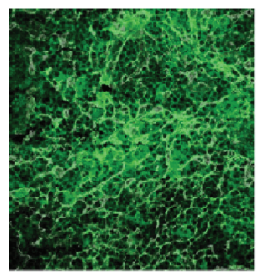

B
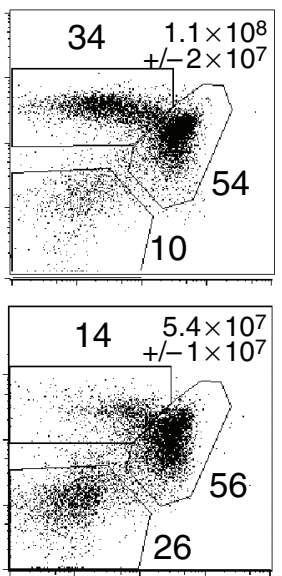

$11 \quad 1.8 \times 10^{7}$ $+/-5 \times 10^{6}$

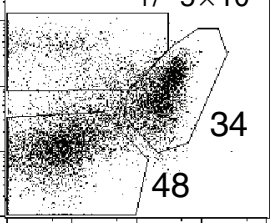

$11 \quad 1.8 \times 10^{7}$ $+-5 \times 10^{6}$

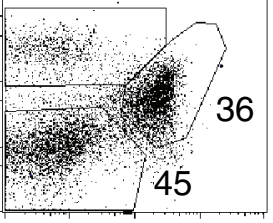

36

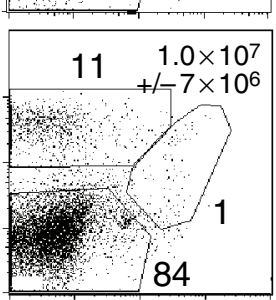

CD8

Fig. 1. Clonal deletion of the 3A9 T-cell receptor (TCR) is proportional to thymic expression of hen egg lysozyme (HEL). HEL transgenes under the control of the insulin, thyroglobulin, metallothionein, and $\mathrm{H} 2 \mathrm{~K}$ promoters were backcrossed to the $\mathrm{B} 10 . \mathrm{Br}$ background. (A) Expression of HEL in transgenic thymi by immunofluorescence correlates with (B) the level of deletion of TCR transgenic thymocytes in TCR:HEL double-transgenic thymi (representative CD4 versus CD8 profiles with the percentage of doublenegative, double-positive, and $\mathrm{CD} 4^{+}$single-positive thymocytes and the average absolute cell number and standard error indicated).

naïve cells to regulatory cells resulting from a competitive process. If this conversion were most efficient at an early developmental time point (either due to increased plasticity in cell fate of the thymocyte or as a property of the stromal microenvironment), then exposure of transgenic thymocytes

to self-antigen in the cortex would result in conversion to regulatory cells (19). Conversely, in the absence of self-antigen in the cortex, a spontaneous stoichiometric conversion may fill up the regulatory compartment: a random process that would result in enrichment upon negative selection of nonregulatory autoreactive cells in the medulla (15). As yet, however, insufficient evidence exists to conclusively prove any model.

Regardless of the mechanism of regulatory cell production, the actively induced anergy and increased proportion of $\mathrm{CD} 25^{+}$cells by the thymic presence of insHEL results in a robust tolerance. Thus, a certain number of HEL-reactive cells are able to escape negative selection and infiltrate the pancreatic islets without induction of clinical autoimmunity, with 3A9 TCR-bearing $\mathrm{CD}^{+}{ }^{+} \mathrm{T}$ cells making up approximately $0.2 \%$ of the splenic lymphoid compartment and only a approximately $20 \%$ incidence of diabetes (Fig. 5).

\section{Autoimmune threshold model}

These two properties of central tolerance induction, a doseresponse curve of clonal deletion and a robust tolerance enforced by $\mathrm{CD} 25^{+}$regulatory cells, allow a system to model genetic defects in the central tolerance pathway. The first principle of the model is that for any given 'specificity' (and this specificity can exist at the epitope, antigen, and even organ level), a maximum number of reactive $\mathrm{T}$ cells can be produced. The second principle is that increasing levels of exposure to self-antigen reduces this number of reactive $\mathrm{T}$ cells, such that many intermediate levels of clonal deletion can be observed. The third principle is that the robust nature of immunological tolerance buffers the presence of a low number of reactive T-cell clones in the peripheral circulation. However, if this number rises above a given threshold of buffering capacity, the chance of autoimmunity increases (Fig. 6A). In a model where the presence of self-antigen also increases the activity of a specific regulatory compartment, the 'autoimmune threshold' would also change with differing thymic self-antigen concentrations (Fig.6A). It should be noted that as the TCRxinsHEL transgenic model has no appreciable conversion of regulatory cells, the simplified model is used here.

An autoimmune threshold can be modeled with either a bipolar distribution or a linear progression of disease state. The specific threshold for autoimmunity will vary from antigen to antigen based on intrinsic properties to the antigen and the expressing organ and extrinsic properties of mechanisms of immune tolerance. However, it is likely that for any given 


\section{$\mathrm{TCR}^{+} \mathrm{HEL}^{+}$host}

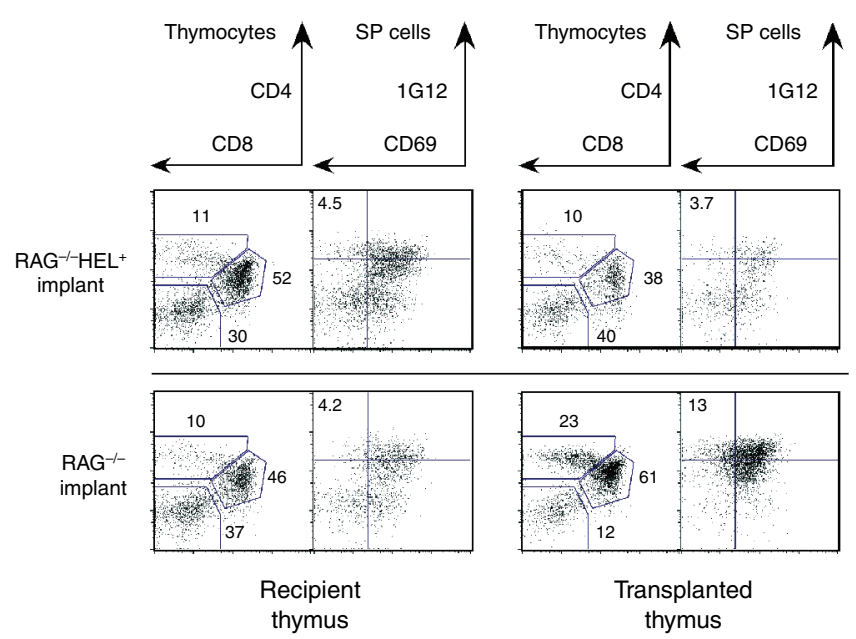

Fig. 2. Ectopic expression of rat insulin hen egg lysozyme promoter (insHEL) in the thymus is sufficient and necessary for deletion of T-cell receptor (TCR) transgenic thymocytes. Non-transgenic and insHEL transgenic thymi from adult $\mathrm{RAG}^{-/-}$mice were transplanted into TCR transgenic or insHEL TCR double-transgenic recipient mice. Thymi are reconstituted with recipient TCR transgenic bone-marrow. Representative flow cytometric profiles are shownfor CD4

antigen, a certain threshold of autoreactive cells can be tolerated without autoimmunity occurring. Experimentally, this allowable threshold of autoreactive cells in the TCRxinsHEL mouse is in the range of $0.2-0.8 \%$ of splenic lymphocytes

\section{$\mathrm{TCR}^{+}$host}

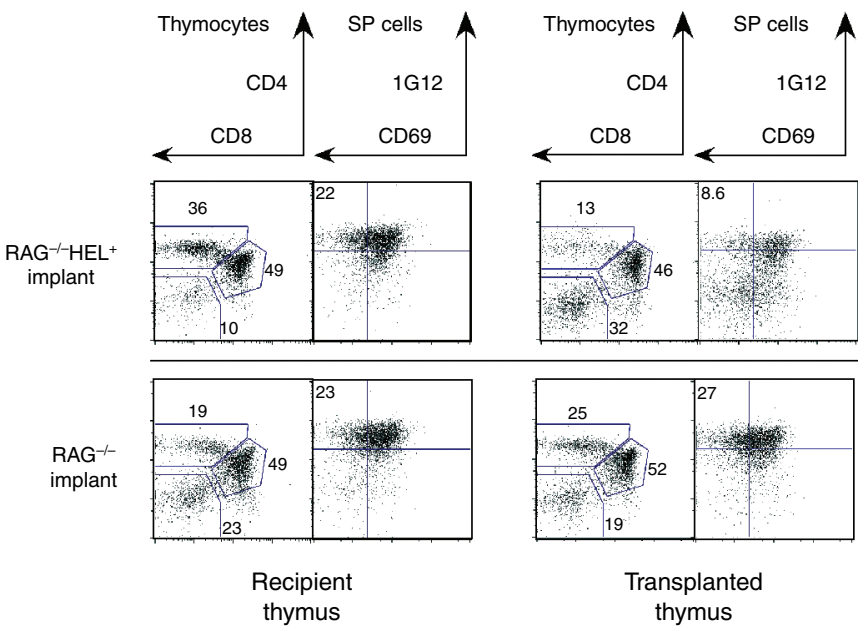

versus CD8 staining of whole thymocytes, showing gates used for double-negative, double-positive and CD4 single-positive (SP) cells, and clonotypic $1 \mathrm{G} 12$ versus $\mathrm{CD} 69$ after gating on $\mathrm{CD} 4{ }^{+} \mathrm{CD} 8^{-}$singlepositive thymocytes, showing the most mature subset of $1 \mathrm{G}^{2} 2^{+} \mathrm{CD} 69^{-}$ cells. TCR transgenic cells are deleted only when the transplanted thymi are transgenic for insHEL, regardless of the peripheral presence of insHEL.

(or rather, lower than $0.2-0.8 \%$ of splenic lymphocytes, as this figure includes HEL-reactive regulatory and anergic cells), as genetic backgrounds that allow a higher proportion of HELreactive cells to escape have a high incidence of diabetes,
A

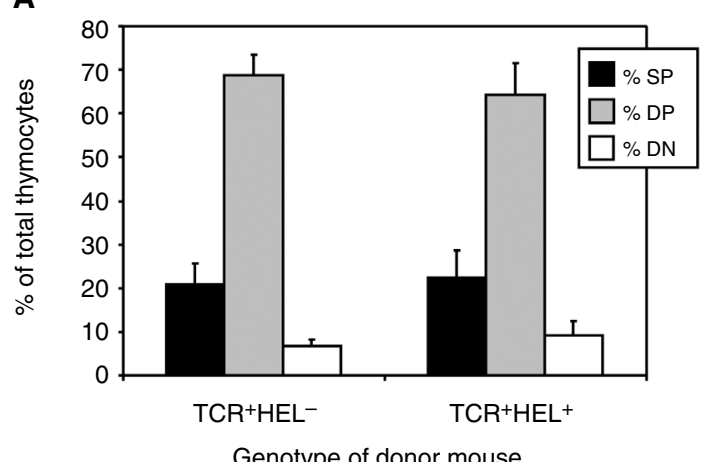

C

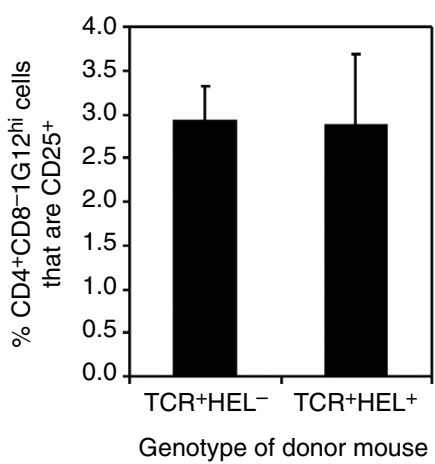

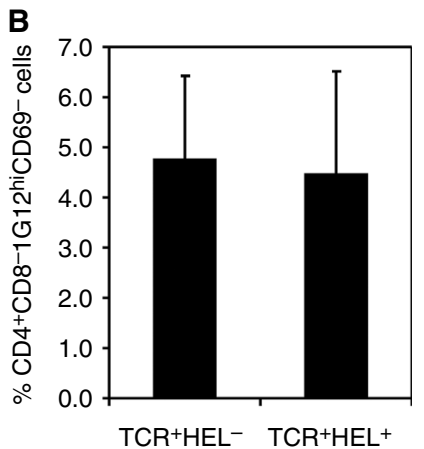

Genotype of donor mouse

D

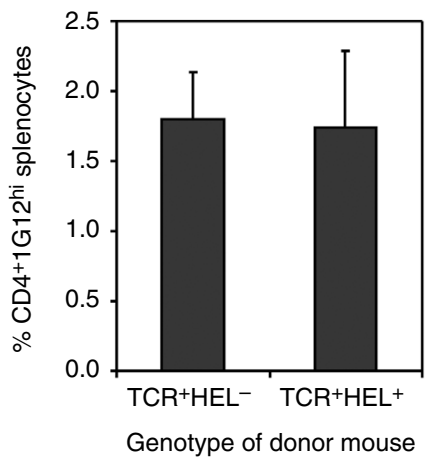

Fig. 3. Presence of the rat insulin hen egg lysozyme promoter (insHEL) transgene in the hemopoietic compartment is insufficient for deletion of T-cell receptor (TCR) transgenic thymocytes. Nontransgenic mice were irradiated and reconstituted with bone marrow from either TCR transgenic $(n=6)$ or TCR transgenic insHEL transgenic $(\mathrm{n}=10)$ mice. Six weeks post-reconstitution, spleen and thymi were analyzed by flow cytometry. Mean and standard deviation for (A) the percentage of thymocytes at the double-negative (DN), double-positive (DP), and $\mathrm{CD}^{+}$singlepositive (SP) stages (B) the percentage of thymocytes at the $1 \mathrm{G} 12^{\text {hi }} \mathrm{CD} 69^{-}$mature $\mathrm{CD} 4^{+}$ single-positive stage. (C) the percentage of $1 \mathrm{G} 12^{\text {high }} \mathrm{CD} 4^{+}$single-positive cells that are $\mathrm{CD}_{25} 5^{+}$, and (D) the percentage of splenic lymphocytes that are $\mathrm{CD} 4^{+} 1 \mathrm{G} 12^{\text {high }}$. Presence of the insHEL transgene in the bone marrow made no significant difference to TCR transgenic T-cell development. 
A

$\mathrm{B} 10^{\mathrm{k}}$

$\mathrm{B} 10^{\mathrm{k}} \mathrm{TCR} \alpha^{0 / 0}$

$\mathrm{B} 10^{\mathrm{k}} \mathrm{RAG} 1^{1 / 0}$

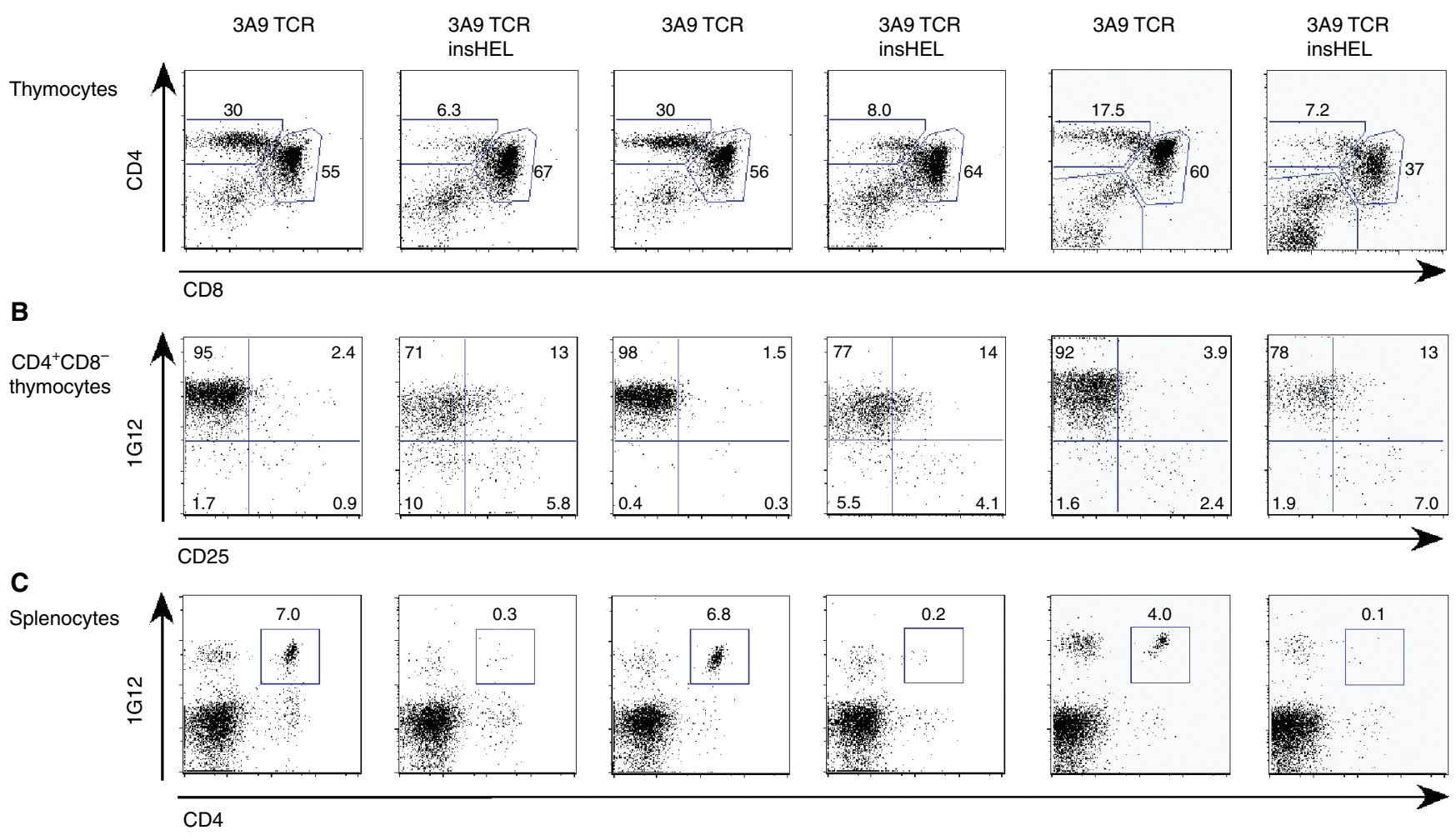

Fig. 4. Effect of rat insulin hen egg lysozyme promoter (insHEL) on 3A9 $\mathrm{T}$-cell receptor (TCR) transgenic $\mathrm{T}$-cell development in wildtype, $\mathrm{TCR} \alpha^{\circ / \circ}$, and $\mathrm{RAG}^{\circ / \circ} \mathrm{B} 10 . \mathrm{Br}$ mice. Representative flow cytometric profiles from 3A9 TCR transgenic mice in the absence of HEL and when carrying the insHEL transgene. Profiles are shown for $\mathrm{B} 10 . \mathrm{Br}$ mice, B10.Br TCR $\alpha^{\circ / \circ}$ mice, and B10.Br RAG ${ }^{\circ}$ mice. Numbers

whereas strains with a lower proportion of HEL-reactive cells have a low incidence of diabetes (Fig. 5).

When using the autoimmune threshold model to calculate relative risk of autoimmunity, several risk factors stand out.

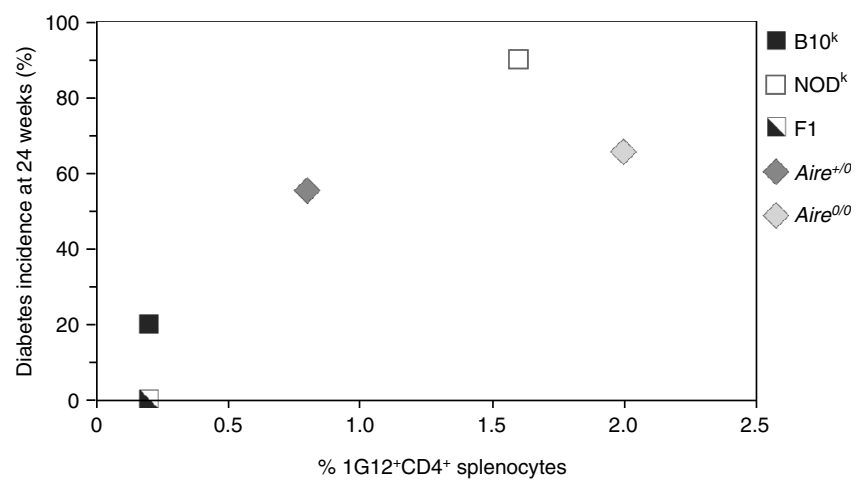

Fig. 5. Scatterplot of the incidence of diabetes at 24 weeks of age and the mean percentage of splenic lymphocytes that are $\mathrm{CD}^{+}{ }^{+} 1 \mathrm{G} 12^{+}$, on TCRxinsHEL double-transgenic mice of various backgrounds. Data aggregated from (66) and (13). indicate the percentage of plotted cells falling within the gates shown. (A) CD4 versus CD8 staining of thymocytes, showing gates used for double-negative, double-positive, and CD4 single-positive cells. (B) Staining for $\mathrm{CD} 25$ and $1 \mathrm{G} 12$, after gating on $\mathrm{CD} 4^{+} \mathrm{CD} 8^{-}$single-positive thymocytes. (C) Staining for CD4 and clonotypic $1 \mathrm{G} 12$ on splenic lymphocytes.

Firstly, the thymic concentration of MHC-peptide is crucial for calculating the risk of autoimmunity. All variables being equal, antigens that are presented in the thymus at a lower concentration are at a greater risk of autoimmunity. Intuitively, all relevant antigens in the body are present in the thymus at an adequate concentration to prevent autoimmunity in the healthy situation. Even the complete absence of thymic peptide would not cause autoimmunity if the target specificity had an extremely high-peripheral tolerance buffering mechanism (such as immunological sequestration). However, obviously, environmental and genetic insults are able to modify this situation to allow autoimmunity.

There are three parameters in this model which can be modified to allow autoimmunity to occur: firstly if the MHC-peptide concentration in the thymus was reduced; secondly if the clonal deletion of thymocytes in response to self-antigen was reduced; and thirdly if the buffering capacity of peripheral tolerance was reduced. In all three cases, the thymic concentration of the antigen dictates the size of the insult required to result in 
A

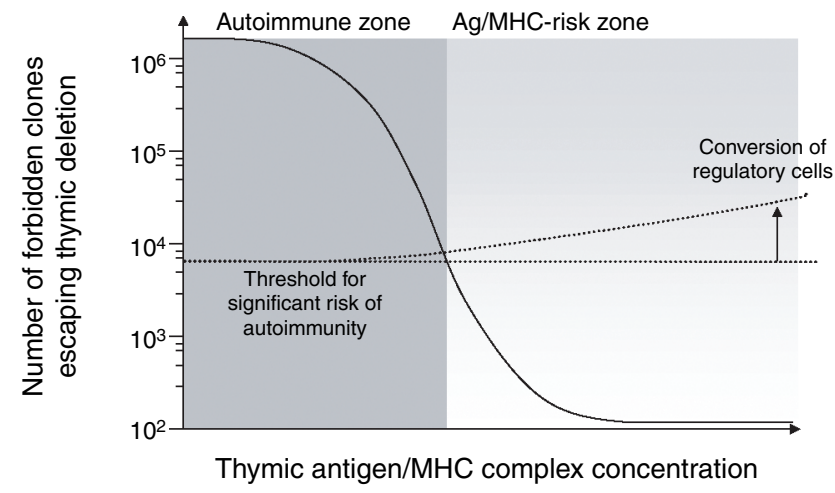

C

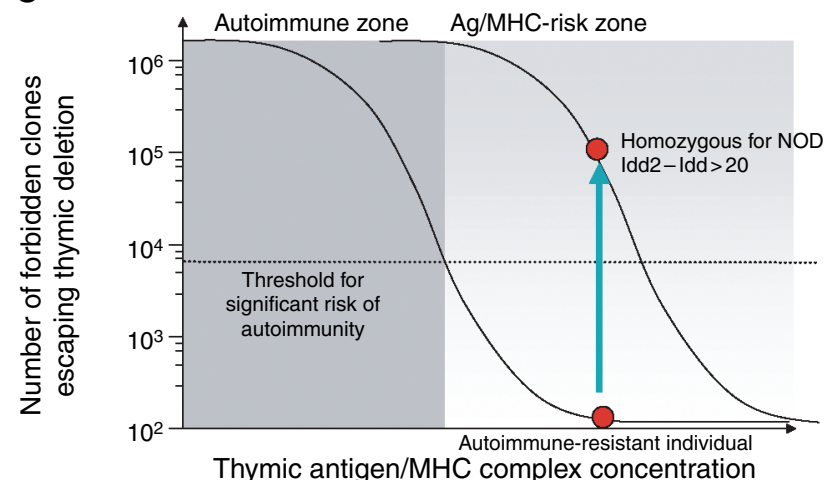

B

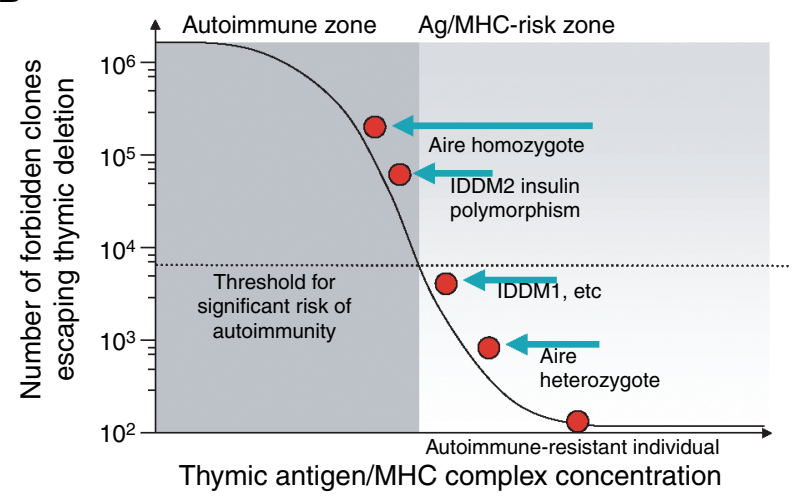

D

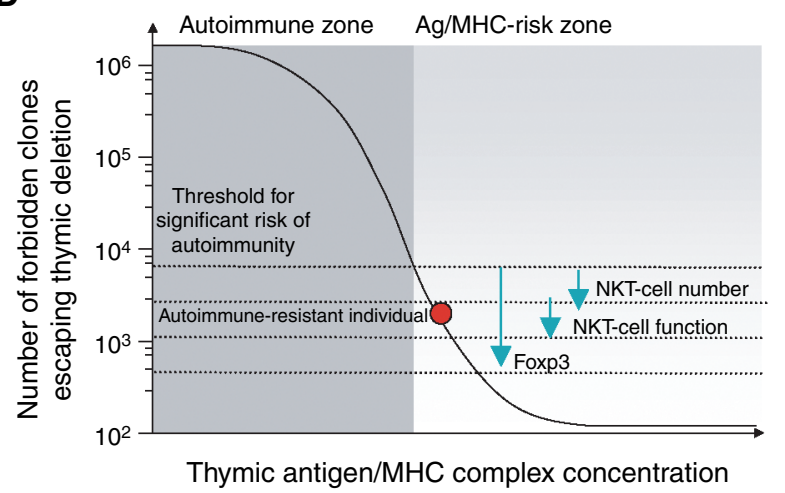

E

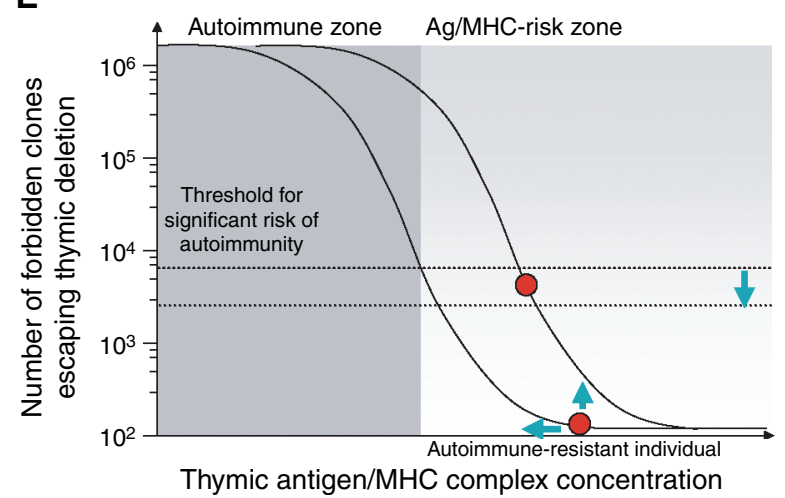

Fig. 6. Schematic illustrating the relationship between the display of tissue antigens in the thymus and the frequency of high-avidity $T$ cells escaping the thymus, and how this relationship is altered by different autoimmune susceptibility genes. (A) The level of clonal deletion of autoreactive thymocytes is proportional to the concentration of major histocompatibility complex (MHC)-self-antigen complexes in the thymus. Peripheral tolerance mechanisms have a finite capacity to suppress remaining autoreactive $\mathrm{T}$ cells, resulting in a threshold for autoimmunity, where thymic concentrations below the intersection of the autoimmune threshold and the clonal deletion curve will be targets for autoimmunity. If autoreactive cells are converted to regulatory cells in the thymus, the threshold for autoimmunity will also vary with thymic concentration of self-antigen. Antigen/MHC combinations that are most limiting normally lie in a 'risk zone', where relatively minor effects can adjust one or more of the parameters to result in the frequency of forbidden clones rising above the threshold for autoimmune susceptibility. (B) Variants in autoimmune regulator (Aire), autoantigen genes, or MHC can elevate the frequency of forbidden clones by diminishing the display of tissue antigens in the thymus, whereas (C) variants in the apoptotic machinery of thymocytes diminish the effect of a given degree of display. (D) Variants in the capacity of peripheral tolerance can result in the induction of autoimmunity without a change in the thymic concentration of antigen or thymocyte response to antigen. (E) Multiple minor changes to all three parameters cooperate to make the nondiabetic (NOD) mouse autoimmune prone. Foxp3, forkhead box P3; IDDM1, insulin-dependant diabetes mellitus 1; NKT, natural killer T cell. 
autoimmunity. Thus, there is a narrow range of thymic concentrations of peripheral autoantigen, a 'risk zone', where small changes translate into an increase in circulating autoreactive cells (Fig. 6A). Antigens expressed at levels above this point may be less likely to become targets of autoimmunity, unless the scale of the parameter change is large.

In the following sections, we review the experiences of ourselves and others in models of genetic defects in central tolerance that demonstrate large changes in a single parameter can result in a significant increase in the risk of autoimmunity. We speculate on polygenic interactions of subtle changes to multiple parameters resulting in autoimmune risk and explain how some genetic lesions may be associated with multiple diseases, while others affect only a single disease, based on the disturbance they make to the autoimmune threshold model.

\section{Disorders affecting antigen-MHC complex concentration}

One class of antigens with a thymic concentration likely to fall into the autoimmune risk zone are the promiscuously expressed proteins. Despite the perception that peripheral tolerance was the primary form of T-cell tolerance towards organ-specific antigens, several examples have emphasized not only the importance of thymic transcripts $(10,11)$ but also the exquisite sensitivity of tolerance towards small changes in thymic concentrations. A common natural polymorphism in the insulin gene promoter (Iddm2) causes only a twofold to threefold decrease in thymic insulin gene expression (20), yet it is strongly linked to diabetes susceptibility $(20,21)$. Another natural polymorphism in SJL mice results in the expression of a splice variant of proteolipid protein (PLP), DM20, in the thymus that lacks the region 116-151. This expression coincides with a very high frequency of $\mathrm{T}$ cells responding to PLP 139-151 observed in the peripheral repertoire, and it presumably contributes to the enhanced susceptibility that these mice show towards experimental autoimmune encephalomyelitis induction (22). Likewise, artificial heterozygous loss of the myelin P0 protein is associated with increasing $\mathrm{T}$-cell responses and autoimmunity to this autoantigen (23).

One of the major advances establishing the significance of thymic promiscuous gene expression has come through the study of APS-1, a monogenic human disorder caused by homozygous mutations in the gene $\operatorname{AIRE}(24,25)$. Clinical manifestations of APS- 1 include a variety of organ-specific autoimmune diseases, the most common of which are hypoparathyroidism and primary adrenocortical failure, accompanied by chronic mucocutaneous candidiasis (26). Diagnosis of APS-1 requires the presence of at least two out of three of these primary disorders. Aire-deficient mice also develop autoimmune symptoms, with a similar range of multiorgan manifestations to that observed in humans, albeit of less apparent severity $(14,27)$.

Aire appears to be a transcription factor, as it localizes in nuclear speckles $(28,29)$, interacts with transcriptional co-activator, cAMP responsive-binding protein (CBP) (30), and is able to activate transcription in luciferase assays $(30,31)$. Expression studies show that it is expressed most highly in rare thymic stromal cells $(13,27,28,32)$, although it may also be expressed in peripheral lymphoid tissue.

Recent studies indicate that Aire actively inhibits organspecific autoimmunity by inducing thymic expression of peripheral antigens in the medulla. Experiments by Anderson et al. (14) found that medullary epithelial cells isolated from Aire knockout mice had lost promiscuous expression of insulin mRNA. Simultaneous research from our laboratory (15) showed that the thymus in Aire knockout mice had lost the ability to delete $3 \mathrm{~A} 9 \mathrm{CD}^{+}{ }^{+} \mathrm{T}$ cells recognizing HEL antigen expressed under control of the insulin promoter (15) (Fig. 7). The loss of Aire abolishes thymic expression of HEL under the insulin promoter, resulting in the maturation and escape from the thymus of large numbers of $\mathrm{CD}^{+}{ }^{+}$HEL-reactive cells (13). These cells make up approximately $2 \%$ of the peripheral lymphoid repertoire in Aire-deficient animals, compared with $0.2 \%$ in controls, and result in a high incidence and very early onset of autoimmune diabetes (Fig. 5). Using the autoimmune threshold model, the loss of Aire induces a major decrease in thymic antigen concentration of Aire-dependent antigens, such that the number of autoreactive cells escaping clonal deletion is beyond the capacity of peripheral tolerance mechanisms to contain (Fig. 6B). There are indications in the literature that Aire may have an effect on the processing or presentation of antigens, with the ubiquitin E3 ligase activity of Aire defined (33), increased proliferation of $\mathrm{T}$ cells upon immunization (27), and a downregulation of interleukin-1 receptor $\alpha$ and MHC class II upon transfection with Aire (34). However, the strongest evidence for the mechanism of autoimmunity in patients with a mutation in Aire correlates with the reduced thymic transcription of tissue-specific antigens: thymic T-cell deletion towards ubiquitous antigens is unchanged in Aire knockout mice (13), and the endocrine-restriction of autoimmune symptoms argues against a vital role in general antigen processing or presentation.

With this information in mind, it is interesting that the clinical condition APS- 1 has a high level of variability in symptoms, especially between populations, such as a higher incidence of hypoparathyroidism in Iranian Jewish patients (35). 
$10^{\mathrm{k}}$
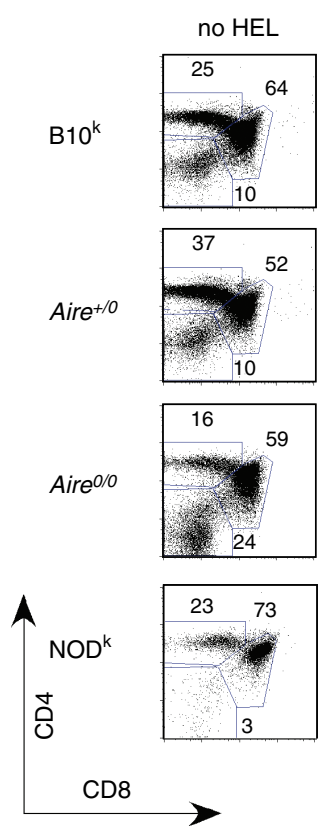
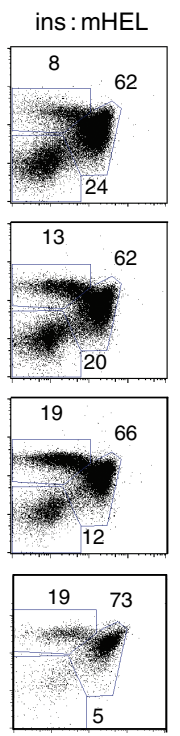
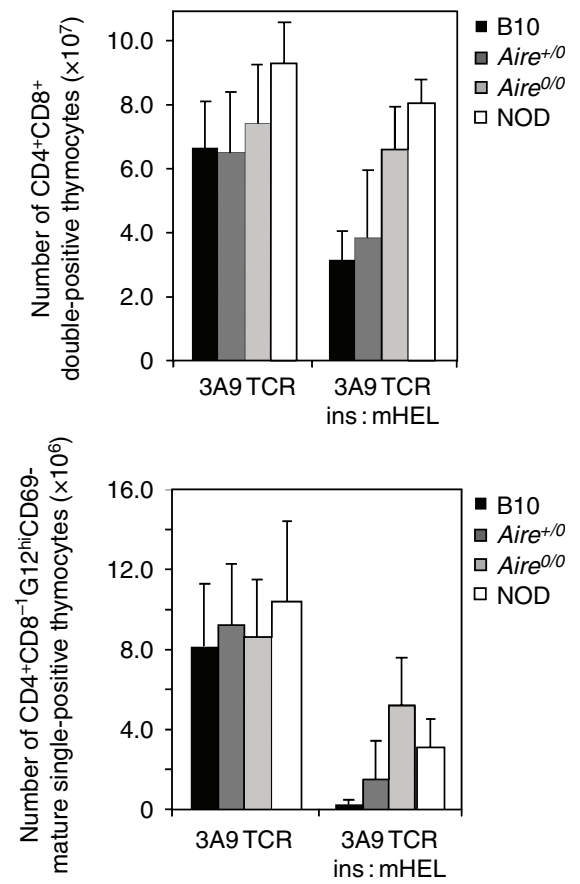

Fig. 7. Defective thymic deletion: a common consequence of autoimmune regulator gene (Aire) defects or non-MHC genes from the non-obese diabetic (NOD) autoimmune mouse strain. Shown are flow cytometric profiles of thymocytes and numerical data obtained from these analyses, from 3A9 T-cell receptor (TCR) transgenic mice with or without a hen egg lysozyme (HEL) transgene controlled by the insulin gene promoter. All mice are $\mathrm{H} 2^{\mathrm{k}}$ congenic, and they differ either in their non-MHC strain background (B10 versus NOD) or in their Aire genotypes (B10 and NOD are both Aire $^{+/+}$).
If the various Aire mutations have the same effect on thymic transcription of ectopic genes, the variability of symptoms across population groups is most likely to relate to environmental or genetic modifiers. In terms of genetic modifiers, lesions that specifically modify the risk of autoimmunity towards a subset of Aire-dependent antigens may influence the symptoms of the disease. Of the various classes of genetic lesions in central tolerance outlined in this review (changes to thymic concentrations of MHC-peptide, changes to the thymocyte dose-response curve, and changes to the regulatory capacity) perhaps the most likely to synergize with Aire mutations are polymorphisms in human leukocyte antigen (HLA). These molecules are highly variable, strongly associated with multiple autoimmune diseases, and can affect thymic repertoire selection of autoreactive $\mathrm{T}$ cell clones. Although several smaller association studies found no linkage or only weak linkage between HLA alleles and APS-1 symptoms (36-38), a larger, more recent study has found haplotype associations for Addison's disease, alopecia, and type 1 diabetes, interestingly with the same polarity of associations as found in the common form of the diseases (39).

What is quite remarkable about the mechanism by which Aire prevents autoimmune disease is that it is so exquisitely sensitive to small reductions in function. On the genetically primed background of the 3A9 TCR insHEL double-transgenic mouse, the loss of a single copy of Aire is sufficient to induce diabetes. The loss of a single copy reduced the amount of Aire each Aire ${ }^{+}$medullary thymic epithelial cell produced, half the transcription of both the endogenous insulin and the RIP transgene, and allowed three times more autoreactive $\mathrm{T}$ cells to mature and escape from the thymus to induce diabetes (13) (Figs 5 and 7).

In humans at least, the AIRE pathway must be partially buffered against small changes on non-susceptible backgrounds. Human carriers of a single-AIRE mutation do not develop the APS- 1 that patients with mutations in both copies suffer. However, although the inheritance pattern of APS-1 indicates a strictly recessive disorder (40), there are anecdotal data of mutations in a single copy of AIRE being associated with human autoimmunity of a less severe form than classically defined APS-1 (41-43). The lack of ubiquitous disease in human carriers of AIRE mutations indicates that no AIREdependent antigens are close enough to the antigen risk concentration that a single mutation in AIRE can act in a polygenic fashion to induce disease. For disease to occur in a subset of human carriers, AIRE heterozygosity would need to act in a complex manner possibly through a polygenic compound hit to thymic antigen concentration. For example, a two to threefold reduction in insulin levels by the Iddm2 allele (20) could have an additive effect on the two-fold decrease with AIRE heterogeneity, with the combined effect pushing the thymic level of insulin into the autoimmune-prone state. Alternatively, the hypothesized decrease in thymic presentation of insulin peptides by the diabetes-associated IDDM1 HLA alleles (44-46) could compound the AIRE mutation. Thus, the study of this rare monogenic trait may be providing us with an 
insight into the manner in which common polygenic traits operate. The subtle effect of AIRE heterogeneity can be compounded into an autoimmune risk factor by other deficiencies in the same pathway (Fig. 6B). Alternatively, a subtle hit on a complementary pathway, such as a reduction in the efficiency of thymocyte clonal deletion or peripheral tolerance (as described below), could synergize with reduced thymic levels to cause autoimmunity. As yet, however, the possibility that heterozygous carriers have an increased prevalence of discrete autoimmune diseases has not yet been systematically addressed.

\section{Disorders affecting the apoptotic response of thymocytes to self-antigen}

A second mechanism by which central tolerance can be broken has been elucidated through the study of the NOD mouse. NOD mice not only exhibit spontaneous type 1 diabetes but also suffer from sialitis and dacryoadenitis and are highly susceptible to experimentally induced autoimmune encephalitis, prostatitis, hemolytic anemia, or systemic lupus (47-56). Autoimmunity is redirected away from the pancreatic-islet $\beta$ cells to different tissue targets in substrains of NOD mice carrying variant $\mathrm{MHC}$ genes $(47,57,58)$. For instance, $\mathrm{H} 2^{\mathrm{k}}$ or $\mathrm{H} 2{ }^{\text {h4 }}$ congenics exhibit autoimmune thyroiditis and variations in non-MHC genes, such as loss of B7.2 or CD47, result in spontaneous autoimmune neuritis or hemolytic anemia, respectively $(49,59)$. Collectively, these observations point to a shared, general propensity towards autoimmunity, with the specific target antigens and tissues varying depending upon additional genetic traits and environmental factors, such as exposure to particular pathogens (60-64).

Over 20 loci have been linked to diabetes development in the NOD mouse (Idd loci), some of which appear to specifically cause susceptibility to diabetes (e.g. Idd1), while others are associated with enhanced susceptibility to a range of autoimmune diseases (e.g. Idd3 and Idd5). The specific mechanism of susceptibility contribution of most of these loci remains to be defined. However, it is likely that a subset of Idd loci result in an inherited propensity towards autoimmunity generally, with the specific target antigens and tissues varying depending upon additional loci and specific environmental factors (62-64).

Investigation into a general autoimmune propensity of the NOD mouse led to the finding that NOD thymocytes have an intrinsic resistance to clonal deletion. In vitro studies by Kishimoto and Sprent (65) showed that semimature thymocytes, intermediate between the immature $\mathrm{CD} 4{ }^{+} \mathrm{CD} 8^{+} \mathrm{DP}$ cells and
$\mathrm{CD} 4{ }^{+} \mathrm{CD} 8{ }^{-}$SP cells, are relatively resistant to cell death when their TCRs are crosslinked in tissue culture with different doses of anti-TCR antibody. During parallel in vivo studies using the 3A9 TCR system, we found an almost complete failure of thymic deletion in TCRxinsHEL mice backcrossed to the NOD.H-2 ${ }^{\mathrm{k}}$ background (Fig. 7) which results in diabetes onset (66) (Fig. 5). Importantly, this reduction in sensitivity to clonal deletion has recently been extended to a MHC class Irestricted TCR transgene (67).

Using the 3A9 TCR transgenic model, backcrossing of additional HEL transgenes to the NOD background has revealed that the in vivo deletion defect is not limited to semi-mature $\mathrm{T}$ cells but applies equally for deletion occurring at all stages of DP-SP thymocyte maturation for $\mathrm{CD} 25^{+}$and $\mathrm{CD} 25^{-}$subsets, and it is observed with varying dose and anatomical source of self-antigen (68). Unlike the Aire defect, the NOD defect is not due to any change in antigen expression in the thymus but acts cell autonomously within the autoreactive thymocytes themselves (66). The comparative analysis of deletion in mice with different HEL transgenes showed that the deletion response of NOD thymocytes was not absolutely crippled, but rather the thymic antigen dose-response is shifted by approximately 10 -fold compared to $\mathrm{T}$ cells with B10 alleles (68). Thus, the NOD thymocytes have an intrinsic resistance to negative selection, resulting in a shift of the antigen dose-response curve to the right (Fig. 6C). For antigens expressed at concentrations close to the threshold of autoimmunity, this shift can result in a decrease in clonal deletion to the point where autoimmunity occurs, while for antigens expressed at much higher levels, the defect in clonal deletion that occurs can be of no physiological consequence (Fig. 6C).

Molecular analyses of thymic deletion in TCRxinsHEL transgenic B10 or NOD animals revealed a set of apoptosisinducing genes that are selectively induced during negative selection in B10 and poorly induced in NOD mice. In particular, the pro-apoptotic Bcl2-family inhibitor Bim was strongly induced in autoreactive thymocytes in B10 mice at the mRNA and protein level, yet it was not detectably induced in the NOD counterparts (68). Given the essential role for Bim as a mediator of thymic clonal deletion, with even loss of a single copy of Bim reducing thymocyte apoptosis $(8,9)$, genetic defects in the Bim pathway are strong candidates for the NOD defect in negative selection and hence susceptibility to autoimmunity.

Further analysis of this trait at the genetic level has identified six loci contributing in an apparently additive manner: four NOD loci conferring susceptibility to defective thymic deletion in homozygotes, and two B10 loci conferring susceptibility to defective thymic deletion in B6/NOD heterozygotes (68). 
Strikingly, all four of the NOD susceptibility loci colocalize with regions previously identified as diabetes susceptibility loci (one of which includes the Bim gene), and the two B10 susceptibility loci colocalize with B10 diabetes susceptibility loci noted previously (69). This colocalization of defective thymic deletion to correctly polarized Idd loci reinforce the earlier prediction that a subset of Idd loci control general susceptibility to autoimmunity by shifting the dose-response curve of thymocytes to allow more forbidden T-cell clones to escape the thymus (Fig. 6C). Furthermore, it indicates that thymocyte sensitivity to clonal deletion can be significantly modified by subtle polygenic changes. Other possible genetic loci that may actively modify the dose-response curve of thymocytes to promote autoimmunity could include global decreases in TCR signaling, such as point mutations in $\zeta$-associated protein of $70 \mathrm{kDa}$ (ZAP-70) (70), or reduced induction of apoptosis from loss of one or both copies of Bim (9).

With a shift in the dose-response curve to the right, autoimmunity is predicted to be targeted primarily against those antigens that have suboptimal levels of thymic expression, such as organ-specific antigens, or to be initiated by lowavidity $\mathrm{T}$ cells to abundant antigens. However, antigens with a higher natural thymic expression level may become target antigens if additional factors decrease their expression or presentation level. Strong contenders for this situation in the NOD mouse include a possible decreased thymic expression of insulin [by an unknown mechanism (71)] mimicking human IDDM2, and the Idd 1 allele $\mathrm{H}_{2}{ }^{\mathrm{g} 7}$ that appears to act in a similar fashion to IDDM1 in humans (44-46). Thus in the NOD mouse, a cluster of Idd loci causing a generalized defect in clonal deletion may be acting in a broad-spectrum autoimmune susceptibility manner, whereas additional genetic lesions may act to specifically enhance the potential for autoimmunity towards pancreatic antigens.

\section{Disorders affecting the capacity of peripheral tolerance}

The third factor in the model that can be affected is the capacity of peripheral tolerance to control escaping autoreactive $\mathrm{T}$ cells. This potential could be made up of several contributing factors: the number of regulatory cells, the regulatory capacity of these cells, the responsiveness of autoreactive cells to regulation, peripheral induction of an anergic or regulatory phenotype in autoreactive cells, and the intrinsic properties of the target organ to shield against autoreactivity. Changes to any of these factors could modify the capacity of peripheral tolerance, leading to a change in the risk of autoimmunity without a change in the number of autoreactive cells produced (Fig. 6D).
The number of regulatory cells

The number of regulatory $\mathrm{T}$ cells (Tregs) generated during thymic selection has a major impact on the number of autoreactive cells that can be tolerated without disease. A series of recent studies (72-74) has found that the human disease immune dysregulation, polyendocrinopathy, enteropathy, $\mathrm{X}$-linked syndrome (IPEX) and the murine equivalent Scurfy are caused by loss-of-function mutations in the gene forkhead box P3 (foxp3). Furthermore, the expression of foxp3 appears to be a consequence of $\mathrm{CD}^{+}{ }^{+}$thymocyte recognition of self (75), and it has been demonstrated to convert a developing thymocyte into a cell with regulatory capacity (72-74). Loss of this regulatory population is associated with the multiple autoimmune symptoms of IPEX and Scurfy, just as similar studies have found that depletion of regulatory $\mathrm{CD} 25^{+}$cells leads to increased autoimmunity (76-78). This parameter does not always require a major monogenic change for an effect to be felt on autoimmunity (especially if held in conjunction with synergistic mutations in complementary pathways), as NOD mice have a minor defect in the number of $\mathrm{CD} 25^{+}$Tregs, which has been associated with increased incidence of diabetes (79).

Invariant natural killer $\mathrm{T}$ cells are another subset with proposed regulatory properties. Activated NKT cells have been demonstrated to inhibit experimental autoimmune encephalitis (80) and type 1 diabetes (81). Therefore, it is of considerable interest that several autoimmune-prone strains have a numerical deficiency in NKT cells, both the SJL strain (82) and the NOD strain (83-85). In the NOD example, at least this deficiency is likely to significantly contribute to the spontaneous autoimmune disease experienced, as transfer of NKT cells prevents diabetes $(83,86)$. The genetic contribution of NKT cell deficiency in the NOD mouse has been calculated, and it is a polygenic trait, with several loci colocalizing with known Idd loci (87). It is likely that a similar trait contributes to type 1 diabetes in the human as well, as a key study has shown a lower frequency of NKT cells in the peripheral blood of diabetic patients (88), although blood levels of NKT cells are not always a good indicator of overall numbers (89).

\section{The regulatory capacity of regulatory cells}

Just as important as the numerical presence of Tregs is the functional capacity to prevent autoreactive cells from initiating autoimmunity. It is unclear as to the molecules required for foxp3-dependent Tregs to suppress autoreactive cells; however, it has been demonstrated that the ability of NKT cells to inhibit autoimmunity is largely dependent on IL-4 production. A defect in IL-4 production by NKT cells would also be 
expected to lower the threshold for the number of autoreactive cells that can be controlled and would thus be associated with autoimmunity. This exact correlation is observed, with NKT cells having deficient IL-4 production in NOD mice $(85,90)$, SJL mice (82), and human diabetic patients (88). It would be expected that the functional deficiency would have an additive effect with numerical deficiency in regards to autoimmunity association. There are probably numerous other examples of minor genetic lesions in the functional capacity of regulatory cells, which will be elucidated with the genetic dissection of autoimmune-prone strains.

\section{Responsiveness of autoreactive cells to regulation}

The activity of regulatory cells is irrelevant if the autoreactive cells are non-responsive to their regulatory capacity. Of the many possible modifiers of responsiveness, activation state is quite important, with memory and activated $\mathrm{T}$ cells being less responsive to the activity of regulatory cells than naïve cells. Therefore, for an antigen at the brink of autoimmunity, the peripheral regulatory network may be capable of suppressing the response while the autoreactive cells are naïve, yet incapable of suppressing the response of activated autoreactive cells. In this situation, an environmental insult that increases the activation status of autoreactive cells could allow the progression to autoimmunity, such as molecular mimicry by foreign antigens, vaccination with self-antigens to induce autoimmunity, infection to create an inflammatory microenvironment and the Toll-like receptor signals (91), or a violation of immunological ignorance through physical injury. There are fewer examples of genetic defects having the same effect; however, one candidate is a non-sense mutation in Cbl-b, resulting in an increased level of TCR density in peripheral T cells. As the tunable threshold for antigen reactivity is determined in the thymus (92), this change in TCR density could result in a higher activation status upon encountering antigen and thus a greater resistance to regulation. Thus, the association of Cbl-b mutations in the Komeda diabetes-prone-rat (93) for increased susceptibility to diabetes could be the result of a decreased responsiveness to regulatory cells. Alternatively, the reverse effect could be created by increased c-Cbl expression in thymocytes, such as is observed in NOD mice (94), decreasing TCR density in the thymus and thus creating an unduly lowtunable threshold.

Peripheral induction of an anergic or regulatory phenotype A fourth factor that affects the peripheral regulatory capacity is the level of peripheral induction of anergic or regulatory cells.
While the thymus appears to be the prime site for anergy induction and regulatory cell conversion, there are multiple examples of these states being induced in the periphery, with one key study showing that ectopic expression in hemopoietic cells can be of importance (95). Recently, upregulation of foxp3 in apparently naïve cells has been observed if stimulation occurs during exposure to transforming growth factor- $\beta$ (96-98), from immature dendritic cells (99) or during high estrogen levels in pregnancy (100). While it is unknown if this phenomenon significantly contributes towards peripheral tolerance, the more characterized conversion of naïve cells into anergic cells has been associated with maintenance of tolerance (101). In the 3A9 model, transgenic $\mathrm{T}$ cells that are chronically stimulated by low levels of self-antigen in the periphery by passive transfer into insHEL transgenic mice lost the ability to subsequently activate HEL-reactive B cells (data not shown).

It is possible that Aire, shown to be central for thymic antigen expression, may also play a role in this peripheral antigen expression and therefore peripheral tolerance via chronic self-exposure. Aire has been detected in peripheral leukocytes at the RNA (102) and protein level $(102,103)$, possibly in lymphocytes, neutrophils, and monocytes (protein) (32), or in $\mathrm{CD}_{14}{ }^{+}$monocytes (RNA) (104), although none of these studies had an Aire knockout control. Bone-marrow chimera experiments indicate that loss of Aire in the peripheral hemopoietic compartment alone is not sufficient to trigger autoimmunity (14); however, a minor contribution of Aire to peripheral tolerance has not been excluded.

Intrinsic properties of the target organ to shield against autoreactivity

The fifth factor that can alter the threshold of autoimmune $\mathrm{T}$ cells that can be tolerated is the intrinsic properties of the target organ. There are several highly characterized organintrinsic protection mechanisms, such as the expression of FasL in the eye (105), the protection of the nervous tissue by the blood-brain barrier (106), and the protective low level of MHC class I expression in several cell types (107). Genetic defects in any of these protection mechanisms could result in the successful initiation of autoimmunity by a lower number of autoreactive cells. One example of such a genetic defect may be pancreatic development in the NOD mouse. The NOD mouse has abnormal pancreatic development with mild infiltration of dendritic cells and macrophages. These abnormalities are lymphocyte-independent [occur in the NOD severe combined immunodeficiency (SCID) mouse] (108), and they 
may contribute to susceptibility towards autoimmune diabetes. In the insHEL transgenic system, male $\mathrm{NOD}^{\mathrm{K}}$ mice have abnormal glucose tolerance (109) and develop spontaneous diabetes $(60 \%$ incidence between 12 and 24 weeks data not shown) if they are insHEL transgenic, even in the absence of the 3A9 TCR transgene to direct T-cell development against the HEL transgene. The strongest evidence is that this progression is due to a combination of $\beta$-islet stress caused by male sex hormones (diabetes does not occur in castrated male mice) and cellular stress caused by over-production of the HEL protein, rather than autoimmunity, as diabetes is observed in male NOD $^{\mathrm{K}}$ insHEL transgenic mice even on the SCID background (data not shown).

\section{Lessons for the polygenic situation}

Major insults to the parameters of T-cell tolerance are able to initiate autoimmunity by themselves. However, multiple minor hits to a single parameter can result in the same impact as a single-monogenic hit, and as we have outlined here, subtle changes in multiple parameters can have a synergistic effect. The NOD mouse is a key model for this polygenic effect. Spontaneous autoimmunity in the NOD mouse relies on multiple genetic insults, which have no effect in the solitary situation on a resistant background. However, the combination of multiple defects (examples of which are given throughout this review) result in subtle shifts in all three parameters (Fig. 6E). The molecular basis of these shifts predicts that some are going to be disease specific in effect (e.g. pre-stressed pancreatic $\beta$ cells and decreased insulin presentation by Idd 1 ), whereas others are going to be more general in effect (e.g. decrease in the dose-response curve of thymocytes or decreased number and function of NKT cells). This division of genetic insults into a functional hierarchy explains the different results observed in correcting NOD autoimmunity: it is easy to inhibit diabetes, as many small factors are all required, but many treatments result in the induction of alternative autoimmune disorders. Thus, instead of correcting disease-specific susceptibility loci, identification and correction of the generalized susceptibility loci should allow prevention of diabetes without allowing the development of alternative autoimmune disease. In the context of human polygenic autoimmune diabetes, where multiple autoimmune diseases cluster in the family, this approach should result in the lowest risk of inadvertently enhancing the progression of an alternative autoimmune disorder by preventing the onset of diabetes.

\section{A note on transgenic mice used in this study}

The 3A9 TCR transgenic mice (110), ILK-3 Ins-HEL transgenic mice (16), TLK3 Tg:mHEL transgenic mice $(16,111)$, ML4 Mt:sHEL transgenic mice (112), and KLK4 H2K:mHEL transgenic mice (113) produced in C57BL/6J mice were backcrossed greater than seven generations to $\mathrm{B} 10 . \mathrm{Br} / \mathrm{SgSnJ}$ (JAX) mice. TCR transgenic Ins-HEL transgenic mice were backcrossed to (B6x129/Sv)F2 Aire ${ }^{+/ 0}$ mice for two generations, to $\mathrm{TCR} \alpha^{\circ}$ mice (JAX) for seven generations, to recombination-activating gene $(R A G)-1^{\circ}$ mice (ARC) for seven generations, and to NOD.H2 ${ }^{\mathrm{k}}$ (114) mice for six generations. Backcross offspring were typed for TCR, HEL, and Aire (27) by polymerase chain reaction and for RAG and TCR $\alpha$ by flow cytometry. Radiation chimeras (16) and thymic transplants (115) were constructed as described previously, except the donor thymi were removed from adult donors. Recipients were analyzed approximately 6 weeks after reconstitution or transplantation. Analyses included immunofluorescence, flow cytometry, and diabetes incidence studies, as previously described $(13,68)$. Animals were cared for and used in accordance with principles outlined by the Australian National University Animal Experimentation Ethics Committee and the current Australian Code of Practice for the Care and Use of Animals for Scientific Purposes.

\section{References}

1. Jaeger C, Hatziagelaki E, Petzoldt R, Bretzel RG. Comparative analysis of organ-specific autoantibodies and celiac disease - associated antibodies in type 1 diabetic patients, their first-degree relatives, and healthy control subjects. Diabetes Care 2001;24:27-32.

2. Prahalad S, Shear ES, Thompson SD, Giannini EH, Glass DN. Increased prevalence of familial autoimmunity in simplex and multiplex families with juvenile rheumatoid arthritis. Arthritis Rheum 2002;46: 1851-1856.
3. Taneja V, Singh RR, Malaviya AN, Anand C, Mehra NK. Occurrence of autoimmune diseases and relationship of autoantibody expression with HLA phenotypes in multicase rheumatoid arthritis families. Scand J Rheumatol 1993;22:152-157.

4. Heinzlef $\mathrm{O}$, et al. Autoimmune diseases in families of French patients with multiple sclerosis. Acta Neurol Scand 2000; 101:36-40.
5. Park YS, Kim TW, Kim WB, Cho BY. Increased prevalence of autoimmune thyroid disease in patients with type 1 diabetes. Korean J Intern Med 2000;15:202-210.

6. Smithson MJ. Screening for thyroid dysfunction in a community population of diabetic patients. Diabet Med 1998;15:148-150.

7. Kappler JW, Roehm N, Marrack P. T cell tolerance by clonal elimination in the thymus. Cell 1987;49:273-280. 
8. Villunger A, et al. Negative selection of semimature CD4(+)8(-) HSA+ thymocytes requires the $\mathrm{BH} 3$-only protein Bim but is independent of death receptor signaling. Proc Natl Acad Sci USA 2004; 101:7052-7057.

9. Bouillet $\mathrm{P}$, et al. BH3-only Bcl-2 family member Bim is required for apoptosis of autoreactive thymocytes. Nature 2002;415:922-926.

10. Hanahan D. Peripheral-antigen-expressing cells in thymic medulla: factors in selftolerance and autoimmunity. Curr Opin Immunol 1998;10:656-662.

11. Kyewski B, Derbinski J, Gotter J, Klein L. Promiscuous gene expression and central Tcell tolerance: more than meets the eye. Trends Immunol 2002;23:364-371.

12. Allen PM, Matsueda GR, Haber E, Unanue ER. Specificity of the $\mathrm{T}$ cell receptor: two different determinants are generated by the same peptide and the I-Ak molecule. J Immunol 1985;135:368-373.

13. Liston A, et al. Gene dosage limiting role of Aire in thymic expression, clonal deletion and organ-specific autoimmunity. J Exp Med 2004;200:1015-1026.

14. Anderson MS, et al. Projection of an Immunological Self-Shadow Within the Thymus by the Aire Protein. Science 2002;298:1395-1401.

15. Liston A, Lesage S, Wilson J, Peltonen L, Goodnow CC. Aire regulates negative selection of organ-specific T cells. Nat Immunol 2003;4:350-354.

16. Akkaraju S, Ho WY, Leong D, Canaan K, Davis MM, Goodnow CC. A range of CD4 T cell tolerance: partial inactivation to organspecific antigen allows nondestructive thyroiditis or insulitis. Immunity 1997;7:255-271.

17. Jordan MS, et al. Thymic selection of CD4+CD25+ regulatory T cells induced by an agonist self-peptide. Nat Immunol 2001;2:301-306.

18. Klein L, Khazaie K, von Boehmer H. In vivo dynamics of antigen-specific regulatory $\mathrm{T}$ cells not predicted from behavior in vitro. Proc Natl Acad Sci USA 2003;100:8886-8891.

19. Kawahata K, et al. Generation of CD4(+)CD25(+) regulatory T cells from autoreactive $\mathrm{T}$ cells simultaneously with their negative selection in the thymus and from nonautoreactive $\mathrm{T}$ cells by endogenous TCR expression. J Immunol 2002;168: 4399-4405.

20. Vafiadis $P$, et al. Insulin expression in human thymus is modulated by INS VNTR alleles at the IDDM2 locus. Nat Genet 1997;15:289-292.
21. Pugliese A, et al. The insulin gene is transcribed in the human thymus and transcription levels correlated with allelic variation at the INS VNTR-IDDM2 susceptibility locus for type 1 diabetes. Nat Genet 1997;15:293-297.

22. Anderson AC, Nicholson LB, Legge KL, Turchin V, Zaghouani H, Kuchroo VK. High frequency of autoreactive myelin proteolipid protein-specific $\mathrm{T}$ cells in the periphery of naive mice: mechanisms of selection of the self-reactive repertoire. J Exp Med 2000;191:761-770.

23. Miyamoto K, Miyake S, Schachner M, Yamamura T. Heterozygous null mutation of myelin P0 protein enhances susceptibility to autoimmune neuritis targeting P0 peptide. Eur J Immunol 2003;33:656-665.

24. Nagamine K, et al. Positional cloning of the APECED gene. Nat Genet 1997;1 17:393-398.

25. The Finnish-German APECED Consortium. An autoimmune disease, APECED, caused by mutations in a novel gene featuring two PHD-type zinc-finger domains. Nat Genet 1997;17:399-403.

26. Betterle C, Greggio NA, Volpato M. Clinical review 93: autoimmune polyglandular syndrome type 1. J Clin Endocrinol Metab 1998;83:1049-1055.

27. Ramsey C, et al. Aire deficient mice develop multiple features of APECED phenotype and show altered immune response. Hum Mol Genet 2002;11:397-409.

28. Heino M, et al. Autoimmune regulator is expressed in the cells regulating immune tolerance in thymus medulla. Biochem Biophys Res Commun 1999;257:821-825.

29. Heino M, et al. RNA and protein expression of the murine autoimmune regulator gene (Aire) in normal, RelB-deficient and in NOD mouse. Eur J Immunol 2000;30:1884-1893.

30. Pitkanen J, et al. The autoimmune regulator protein has transcriptional transactivating properties and interacts with the common coactivator CREB-binding protein. J Biol Chem 2000;275:16802-16809.

31. Bjorses $\mathrm{P}$, et al. Mutations in the AIRE gene: effects on subcellular location and transactivation function of the autoimmune polyendocrinopathy-candidiasis-ectodermal dystrophy protein. Am J Hum Genet 2000;66:378-392.

32. Bjorses P, Pelto-Huikko M, Kaukonen J, Aaltonen J, Peltonen L, Ulmanen I. Localization of the APECED protein in distinct nuclear structures. Hum Mol Genet 1999;8:259-266.

33. Uchida D, et al. AIRE functions as an E3 ubiquitin ligase. J Exp Med 2004;199:167-172.
34. Sato K, et al. Aire down-regulates multiple molecules that have contradicting immuneenhancing and immune-suppressive functions. Biochem Biophys Res Commun 2004;318:935-940.

35. Zlotogora J, Shapiro MS. Polyglandular autoimmune syndrome type I among Iranian Jews. J Med Genet 1992;29:824-826.

36. Maclaren NK, Riley WJ. Inherited susceptibility to autoimmune Addison's disease is linked to human leukocyte antigens-DR3 and/or DR4, except when associated with type I autoimmune polyglandular syndrome. J Clin Endocrinol Metab 1986;62:455-459.

37. Huang W, et al. Although DR3-DQB1*0201 may be associated with multiple component diseases of the autoimmune polyglandular syndromes, the human leukocyte antigen DR4-DQB $1 * 0302$ haplotype is implicated only in beta-cell autoimmunity. J Clin Endocrinol Metab 1996;81:2559-2563.

38. Ahonen P, Koskimies S, Lokki ML, Tiilikainen A, Perheentupa J. The expression of autoimmune polyglandular disease type I appears associated with several HLA-A antigens but not with HLA-DR. J Clin Endocrinol Metab 1998;66:1152-1157.

39. Halonen M, et al. AIRE mutations and human leukocyte antigen genotypes as determinants of the autoimmune polyendocrinopathycandidiasis-ectodermal dystrophy phenotype. $\mathrm{J}$ Clin Endocrinol Metab 2002;87:2568-2574.

40. Ahonen P. Autoimmune polyendocrinopathy candidosis - ectodermal dystrophy (APECED): autosomal recessive inheritance. Clin Genet 1985;27:535-542.

41. Buzi F, et al. Autoimmune polyendocrinopathy-candidiasis-ectodermal dystrophy syndrome: time to review diagnostic criteria? J Clin Endocrinol Metab 2003;88:3146-3148.

42. Cetani F, et al. A novel mutation of the autoimmune regulator gene in an Italian kindred with autoimmune polyendocrinopathy-candidiasis-ectodermal dystrophy, acting in a dominant fashion and strongly cosegregating with hypothyroid autoimmune thyroiditis. J Clin Endocrinol Metab 2001;86:4747-4752.

43. Soderbergh A, et al. Autoantibodies against aromatic 1-amino acid decarboxylase identifies a subgroup of patients with Addison's disease. J Clin Endocrinol Metab 2000;85:460-463.

44. Corper AL, et al. A structural framework for deciphering the link between I-Ag7 and autoimmune diabetes. Science 2000;288:505-511. 
45. Ogino T, Sato K, Miyokawa N, Kimura S, Katagiri M. Importance of GAD65 peptides and I-Ag7 in the development of insulitis in nonobese diabetic mice. Immunogenetics 2000;51:538-545.

46. Stratmann T, et al. The I-Ag7 MHC class II molecule linked to murine diabetes is a promiscuous peptide binder. J Immunol 2000;165:3214-3225.

47. Wicker LS, Todd JA, Peterson LB. Genetic control of autoimmune diabetes in the NOD mouse. Annu Rev Immunol 1995;13:179-200.

48. Baker D, Rosenwasser OA, O’Neill JK, Turk JL. Genetic analysis of experimental allergic encephalomyelitis in mice. J Immunol 1995;155:4046-4051.

49. Oldenborg PA, Gresham HD, Chen Y, Izui S, Lindberg FP. Lethal autoimmune hemolytic anemia in CD47-deficient nonobese diabetic (NOD) mice. Blood 2002;99:3500-3504.

50. Boulard O, Fluteau G, Eloy L, Damotte D, Bedossa P, Garchon HJ. Genetic analysis of autoimmune sialadenitis in nonobese diabetic mice: a major susceptibility region on chromosome 1. J Immunol 2002;168:4192-4201.

51. Zaccone P, Fehervari Z, Blanchard L, Nicoletti F, Edwards CK III, Cooke A. Autoimmune thyroid disease induced by thyroglobulin and lipopolysaccharide is inhibited by soluble TNF receptor type I. Eur J Immunol 2002;32:1021-1028.

52. Braley-Mullen H, Sharp GC, Medling B, Tang H. Spontaneous autoimmune thyroiditis in NOD.H-2h4 mice. J Autoimmun 1999;12:157-165.

53. Rivero VE, Cailleau C, Depiante-Depaoli M, Riera CM, Carnaud C. Non-obese diabetic (NOD) mice are genetically susceptible to experimental autoimmune prostatitis (EAP). J Autoimmun 1998;11:603-610.

54. Takahashi M, Ishimaru N, Yanagi K, Haneji N, Saito I, Hayashi Y. High incidence of autoimmune dacryoadenitis in male nonobese diabetic (NOD) mice depending on sex steroid. Clin Exp Immunol 1997; 109:555-561.

55. Ridgway WM, Fasso M, Lanctot A, Garvey C, Fathman CG. Breaking self-tolerance in nonobese diabetic mice. J Exp Med 1996;183:1657-1662.

56. Baxter AG, et al. Mycobacteria precipitate an SLE-like syndrome in diabetes-prone NOD mice. Immunology 1994;83:227-231.

57. Wicker LS. Major histocompatibility complex-linked control of autoimmunity. J Exp Med 1997;186:973-975.

58. Vyse TJ, Todd JA. Genetic analysis of autoimmune disease. Cell 1996;85:311-318.
59. Salomon B, et al. Development of spontaneous autoimmune peripheral polyneuropathy in B7-2-deficient NOD mice. J Exp Med 2001;194:677-684.

60. Baxter AG. Immunogenetics and the cause of autoimmune disease. Autoimmunity 1997;25:177-189.

61. Marrack P, et al. Autoimmune disease: why and where it occurs. Nat Med 2001;7:899-905.

62. Wicker LS, Miller BJ, Fischer PA, Pressey A, Peterson LB. Genetic control of diabetes and insulitis in the nonobese diabetic mouse. Pedigree analysis of a diabetic H-2nod/b heterozygote. J Immunol 1989;142:781-784.

63. Bias WB, Reveille JD, Beaty TH, Meyers DA, Arnett FC. Evidence that autoimmunity in man is a Mendelian dominant trait. Am J Hum Genet 1986;39:584-602.

64. Lesage S, Goodnow CC. Organ-specific autoimmune disease: a deficiency of tolerogenic stimulation. J Exp Med 2001;194:F31-F36.

65. Kishimoto H, Sprent J. A defect in central tolerance in NOD mice. Nat Immunol 2001;2:1025-1031.

66. Lesage S, Hartley SB, Akkaraju S, Wilson J, Townsend M, Goodnow CC. Failure to censor forbidden clone of CD4 T cells in autoimmune diabetes. J Exp Med 2002;196:1175-1188.

67. Choisy-Rossi CM, Holl TM, Pierce MA, Chapman HD, Serreze DV. Enhanced pathogenicity of diabetogenic $\mathrm{T}$ cells escaping a non-MHC gene-controlled near death experience. J Immunol 2004;173:3791-3800.

68. Liston A, et al. Generalized resistance to thymic deletion in the NOD mouse: a polygenic trait characterized by defective induction of Bim. Immunity 2004, (in press).

69. Ghosh S, et al. Polygenic control of autoimmune diabetes in nonobese diabetic mice. Nat Genet 1993;4:404-409.

70. Sakaguchi N, et al. Altered thymic T-cell selection due to a mutation of the ZAP-70 gene causes autoimmune arthritis in mice. Nature 2003;426:454-460.

71. Brimnes MK, Jensen T, Jorgensen TN, Michelsen BK, Troelsen J, Werdelin O. Low Expression of Insulin in the Thymus of Nonobese Diabetic Mice. J Autoimmun 2002;19:183-193.

72. Hori S, Nomura T, Sakaguchi S. Control of regulatory $\mathrm{T}$ cell development by the transcription factor Foxp3. Science 2003;299:1057-1061.

73. Fontenot JD, Gavin MA, Rudensky AY. Foxp3 programs the development and function of CD4+CD25+ regulatory T cells. Nat Immunol 2003;4:330-336.
74. Khattri R, Cox T, Yasayko SA, Ramsdell F. An essential role for Scurfin in CD4+CD25+ T regulatory cells. Nat Immunol

2003;4:337-342.

75. Hsieh CS, Liang Y, Tyznik AJ, Self SG, Liggitt D, Rudensky AY. Recognition of the Peripheral Self by Naturally Arising CD25(+) CD4(+) T Cell Receptors. Immunity 2004;21:267-277.

76. Laurie KL, et al. The role of $\mathrm{CD} 4+\mathrm{CD} 25+$ immunoregulatory $\mathrm{T}$ cells in the induction of autoimmune gastritis. Immunol Cell Biol 2002;80:567-573.

77. McHugh RS, et al. Cutting edge: depletion of CD4+CD25+ regulatory T cells is necessary, but not sufficient, for induction of organspecific autoimmune disease. J Immunol 2002;168:5979-5983.

78. Itoh $\mathrm{M}$, et al. Thymus and autoimmunity: production of $\mathrm{CD} 25+\mathrm{CD} 4+$ naturally anergic and suppressive $\mathrm{T}$ cells as a key function of the thymus in maintaining immunologic selftolerance. J Immunol 1999;162:5317-5326.

79. Wu AJ, Hua H, Munson SH, McDevitt HO. Tumor necrosis factor-alpha regulation of CD4+CD25+ T cell levels in NOD mice. Proc Natl Acad Sci USA 2002;99:12287-12292.

80. Singh AK, et al. Natural killer T cell activation protects mice against experimental autoimmune encephalomyelitis. J Exp Med 2001;194:1801-1811.

81. Sharif $\mathrm{S}$, et al. Activation of natural killer $\mathrm{T}$ cells by alpha-galactosylceramide treatment prevents the onset and recurrence of autoimmune Type 1 diabetes. Nat Med 2001;7:1057-1062.

82. Yoshimoto T, Bendelac A, Hu-Li J, Paul WE. Defective IgE production by SJL mice is linked to the absence of $\mathrm{CD} 4+$, NK1.1+ T cells that promptly produce interleukin 4. Proc Natl Acad Sci USA 1995;92:11931-11934.

83. Baxter AG, Kinder SJ, Hammond KJ, Scollay R, Godfrey DI. Association between alphabeta TCR+CD4-CD8- T-cell deficiency and IDDM in NOD/Lt mice. Diabetes 1997;46:572-582.

84. Godfrey DI, Kinder SJ, Silvera P, Baxter AG. Flow cytometric study of $\mathrm{T}$ cell development in NOD mice reveals a deficiency in alphabetaTCR +CDR-CD8- thymocytes. J Autoimmun 1997;10:279-285.

85. Gombert JM, Herbelin A, Tancrede-Bohin E, Dy M, Carnaud C, Bach JF. Early quantitative and functional deficiency of $\mathrm{NK} 1^{+}$-like thymocytes in the NOD mouse. Eur J Immunol 1996;26:2989-2998. 
86. Hammond KJ, Poulton LD, Palmisano LJ, Silveira PA, Godfrey DI, Baxter AG. alpha/ beta-T cell receptor (TCR) +CD4-CD8(NKT) thymocytes prevent insulin-dependent diabetes mellitus in nonobese diabetic (NOD)/Lt mice by the influence of interleukin (IL)-4 and/or IL-10. J Exp Med 1998;187:1047-1056.

87. Esteban LM, et al. Genetic control of NKT cell numbers maps to major diabetes and lupus loci. J Immunol 2003;171:2873-2878.

88. Wilson SB, et al. Extreme Th1 bias of invariant Valpha24JalphaQ T cells in type 1 diabetes. Nature 1998;391:177-181.

89. Berzins SP, et al. Systemic NKT cell deficiency in NOD mice is not detected in peripheral blood: implications for human studies. Immunol Cell Biol 2004;82:247-252.

90. Poulton LD, et al. Cytometric and functional analyzes of NK and NKT cell deficiencies in NOD mice. Int Immunol 2001;13:887-896.

91. Yang Y, Huang CT, Huang X, Pardoll DM. Persistent Toll-like receptor signals are required for reversal of regulatory $\mathrm{T}$ cellmediated CD8 tolerance. Nat Immunol 2004;5:508-515.

92. Viola A, Lanzavecchia A. T cell activation determined by $\mathrm{T}$ cell receptor number and tunable thresholds. Science 1996;273:104-106.

93. Yokoi, N, et al. Cblb is a major susceptibility gene for rat type 1 diabetes mellitus. Nat Genet 2001;31:391-394.

94. Salojin K, et al. Impaired plasma membrane targeting of Grb2-murine son of sevenless (mSOS) complex and differential activation of the Fyn-T cell receptor (TCR)-zeta-Cbl pathway mediate $\mathrm{T}$ cell hyporesponsiveness in autoimmune nonobese diabetic mice. J Exp Med 1997;186:887-897.

95. Zheng X, Yin L, Liu Y, Zheng P. Expression of tissue-specific autoantigens in the hematopoietic cells leads to activationinduced cell death of autoreactive T cells in the secondary lymphoid organs. Eur J Immunol 2004;34:3126-3134.
96. Chen W, et al. Conversion of peripheral CD4+CD25- naive T cells to CD4+CD25+ regulatory $\mathrm{T}$ cells by TGF-beta induction of transcription factor Foxp3. J Exp Med 2003;198:1875-1886.

97. Peng Y, Laouar Y, Li MO, Green EA, Flavell RA. TGF-beta regulates in vivo expansion of Foxp3-expressing CD4+CD25+ regulatory $\mathrm{T}$ cells responsible for protection against diabetes. Proc Natl Acad Sci USA 2004;101:4572-4577.

98. Park HB, Paik DJ, Jang E, Hong S, Youn J. Acquisition of anergic and suppressive activities in transforming growth factorbeta-costimulated CD4+CD25- T cells. Int Immunol 2004;16:1203-1213.

99. Verhasselt V, Vosters O, Beuneu C, Nicaise C, Stordeur P, Goldman M. Induction of FOXP3-expressing regulatory CD4pos T cells by human mature autologous dendritic cells. Eur J Immunol 2004;34:762-772.

100. Polanczyk MJ, et al. Cutting edge: estrogen drives expansion of the CD4+CD25+ regulatory $\mathrm{T}$ cell compartment. J Immunol 2004;173:2227-2230.

101. Schwartz RH. T Cell Anergy. Annu Rev Immunol 2004;21:305-334.

102. Adamson KA, Pearce SH, Lamb JR, Seckl JR, Howie SE. A comparative study of mRNA and protein expression of the autoimmune regulator gene (Aire) in embryonic and adult murine tissues. J Pathol 2004;202:180-187.

103. Rinderle C, Christensen HM, Schweiger S, Lehrach H, Yaspo ML. AIRE encodes a nuclear protein colocalizing with cytoskeletal filaments: altered subcellular distribution of mutants lacking the PHD zinc fingers. Hum Mol Genet 1999;8:277-290.

104. Kogawa K, et al. Expression of AIRE gene in peripheral monocyte/dendritic cell lineage. Immunol Lett 2002;80:195-198.

105. Griffith TS, Brunner T, Fletcher SM, Green DR, Ferguson TA. Fas ligand-induced apoptosis as a mechanism of immune privilege. Science 1995;270:1189-1192.
106. Pachter JS, de Vries HE, Fabry Z. The bloodbrain barrier and its role in immune privilege in the central nervous system. J Neuropathol Exp Neurol 2003;62:593-604.

107. Ito T, Ito N, Bettermann A, Tokura Y, Takigawa M, Paus R. Collapse and restoration of MHC class-I-dependent immune privilege: exploiting the human hair follicle as a model. Am J Pathol 2004; 164:623-634.

108. Homo-Delarche F. Is pancreas development abnormal in the nonobese diabetic mouse, a spontaneous model of type I diabetes? Braz J Med Biol Res 2001;34:437-447.

109. Socha L, Silva D, Lesage S, Goodnow C, Petrovsky N. The role of endoplasmic reticulum stress in nonimmune diabetes: NOD.k iHEL, a novel model of beta cell death. Ann N Y Acad Sci 2003;1005:178-183.

110. Ho WY, Cooke MP, Goodnow CC, Davis MM. Resting and anergic B cells are defective in CD28-dependent costimulation of naive CD4+ T cells. J Exp Med 1994;179:1539-1549.

111. Akkaraju S, Canaan K, Goodnow CC. Selfreactive $B$ cells are not eliminated or inactivated by autoantigen expressed on thyroid epithelial cells. J Exp Med 1997; 186:2005-2012.

112. Adelstein $S$, et al. Induction of self-tolerance in $\mathrm{T}$ cells but not B cells of transgenic mice expressing little self antigen. Science 2001;251:1223-1225.

113. Hartley SB, Crosbie J, Brink R, Kantor AB, Basten A, Goodnow CC. Elimination from peripheral lymphoid tissues of self-reactive B lymphocytes recognizing membranebound antigens. Nature 1991;353:765-769.

114. Podolin PL, Pressey A, DeLarato NH, Fischer PA, Peterson LB, Wicker LS. I-E+ nonobese diabetic mice develop insulitis and diabetes. J Exp Med 1993;1 18:793-803.

115. Berzins SP, Boyd RL, Miller JF. The role of the thymus and recent thymic migrants in the maintenance of the adult peripheral lymphocyte pool. J Exp Med 1998;187:1839-1848. 